\title{
多模态建构下的无机化学课程学习体验与感受
}

杨丽锦, 苏敏, 黄采薇, 魏灵灵, 马艺, 王晓明, 焦桓 ${ }^{*}$

陕西师范大学化学化工学院, 西安 710119

摘要: 陕西师范大学化学化工学院无机化学课程组根据课程内容和学生学习特点, 有针对性地设计并采取了不同的授课 方式, 构建了多模态教学方式, 尝试了创新型课堂, 以调动学生的学习积极性, 培养学生的自主学习能力。本文从学生 的角度出发, 依据无机化学课程学习情况, 对不同的教学方式下的学习感受进行了总结, 剖析了学生在多模态建构下的 无机化学课程中的学习体验与感受, 以期在教学改革的探索中实现师生共学相长, 共同提升教学质量, 打造适合提升学 生综合能力的 “入门课程”。

关键词: 无机化学; 多模态建构; 创新型课堂; 学生自主学习能力; 学生中心教学模式 中图分类号: G64; O6

\section{Learning Experience and Feeling of Inorganic Chemistry Course with Multi-Modal Construction}

Lijin Yang, Min Su, Caiwei Huang, Lingling Wei, Yi Ma, XiaoMing Wang, Huan Jiao *

School of Chemistry \& Chemical Engineering, Shaanxi Normal University, Xi'an 710119, China.

\begin{abstract}
According to the course content and students' learning characteristics, the inorganic chemistry teaching group at School of Chemistry \& Chemical Engineering, Shaanxi Normal University, has adopted different teaching methods, constructed multi-modal teaching methods, and tried innovative classrooms to mobilize students' learning enthusiasm and cultivate students' independent learning ability. In this article, the different teaching methods based on the basic data of the teaching and learning of inorganic chemistry courses has been summarized from the perspective of the students. It has also analyzed the learning experience and feelings of students in the teaching of inorganic chemistry courses under the multi-modal construction. In the exploration of teaching reform, teachers and students can learn from each other, improve the teaching quality together, and finally create a "first-class course" suitable for improving students' comprehensive ability.
\end{abstract}

Key Words: Inorganic chemistry; Multi-mode construction; Innovative class;

Students' independent learning ability; Student-centered teaching mode

无机化学作为化学学科的专业基础课, 是联系高中与大学专业知识的纽带, 也是改变学生学习 方式的桥梁课程, 对培养学生化学思维具有很好的启迪作用 ${ }^{[1]}$ 。因此, 无机化学课程能否体现化学 学科的专业性、是否能够充分展现出大学课程学习的特点就显得尤为重要。2018年8月, 教育部印发 了《关于狠抓新时代全国高等学校本科教育工作会议精神落实的通知》 (以下简称《通知》) ${ }^{[2]}$ 。《通 知》中强调, 我国高等学校本科教育要努力建设一流本科、做强一流专业、培养一流人才, 创新课

收稿: 2021-06-08; 录用: 2021-08-14; 网络发表: 2021-09-27

“通讯作者, Email: jiaohuan@snnu.edu.cn

基金资助: 陕西省教改重点项目; 陕西师范大学教学改革综合研究项目(19JG30, 21JG01, 21JG03); 陕西师范大学一流课程建设项目 
程建设模式, 创新教学组织形态。培养学生解决复杂问题的综合能力和提升逻辑思维水平, 注重知 识、能力、素质的结合, 让课程内容兼具前沿性和时代性, 让课程有难度、学生有挑战, 改变教学 “满堂灌” “我讲你听” 的传统模式, 充分发挥学生的学习主动性已经成为当下大学课程教学和大 学生学习的主要诉求。

无机化学课程内容繁杂, 知识体系庞杂, 传统课堂教学模式发挥着重要作用。为加快课程建设 进程, 让无机化学教学不仅传授化学知识, 更为重要的是彰显其训练学生的科学思维, 培养学生的 科学精神与品德的作用 ${ }^{[3]}$, 陕西师范大学化学化工学院无机化学课程组的授课教师根据课程内容和 学生个人专业素养发展需求, 先后设计并开展了课堂内容延伸、主题研讨与汇报、思维导图与章节 总结、学生自主设计课堂等多项课堂教学活动。与此同时让学生从活动中逐步掌握获取、管理和展 示知识的技能, 在能力层面上期望通过教学内容研究和教学模式创新, 以实现个人综合能力提升的 要求: 一是能够进行综合分析、理论计算和解决一般化学问题; 二是能够运用化学知识初步解决一 些与生活息息相关的实际性问题; 三是能够适应现代技术发展的更新能力和创新意识, 并为后续学 习打下必要且扎实的知识、能力与思维基础。

为了对教学模式进行检验和反思, 真正体现以学生为中心的教学宗旨, 充分调动学生的学习积 极性, 本文以某班级全体55名学生为研究对象, 通过访谈和问卷调查获得了学生对课程教学的直接 感受, 在此基础上剖析了学生在多模态建构下的无机化学课程学习中的思考、反思与期盼, 以期能 够在无机化学课程教学改革和学习的探索中实现师生共学相长, 共同提升课堂质量, 推进学生综合 素质的提升。

\section{1 无机化学课程开设情况}

化学类专业第一学年开设的无机化学课程内容主要包括化学基本原理、物质结构基础和元素化 学三大板块, 每个学期安排 54 个授课课时及36课时辅导课。

课程是人才培养的核心要素, 能让学生从大学里受益最直接、最显效、最核心的是课程 ${ }^{[4]}$ 。因 此, 课程组教师秉持教育规律与教育价值相结合的教育理念, 对该班级无机化学课程采用了 “传 统+创新” 的教学模式(图1)。从整体来看, 各种教学活动的设计和开展以提升学生综合能力为目 的 ${ }^{[5]}$, 以教学内容为依托, 以学生为主体, 以课堂为阵地, 通过课堂讲授、布置课后作业、辅导课习 题讲解等多重举措夯实学生基础, 进一步根据无机化学的课程内容安排, 结合课堂进度与知识学习 特点对学生能力培养进行规划, 设计并开展以学习小组为单位、多种形式的课堂教学活动, 不断拓 展延伸，利用周末等课余时间实现各项能力的对点突破，引导和规范学生综合能力提升。

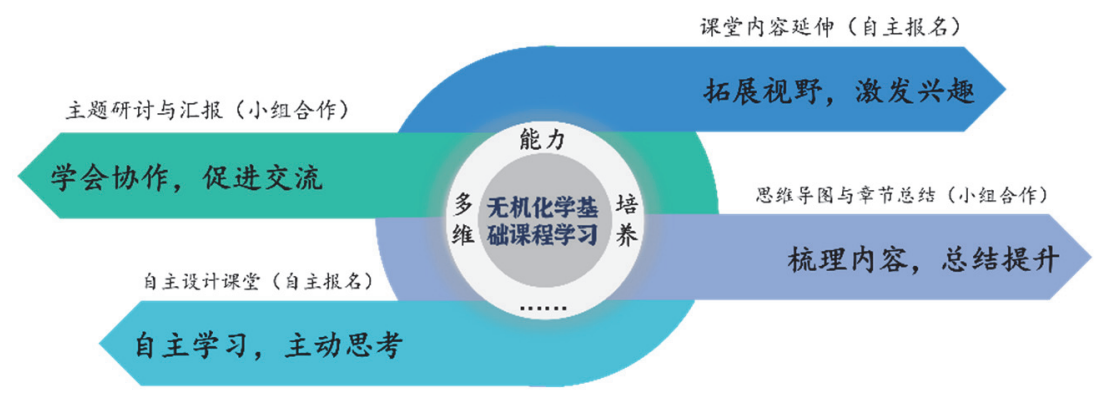

图1 课程教学活动支撑关系图

在学习化学基本原理和物质结构基础部分过程中, 授课教师主要开展了课堂内容延伸、主题研 讨与汇报两项课堂教学活动, 在培养学生学习兴趣的同时以课程大作业为载体, 通过组建由 5 到 7 名 学生组成的学习小组, 每个学习小组在一学期内完成一个主题的研讨和汇报, 小组成员分工协作完 成文献查阅、资料整合和分析、材料撰写和组织以及现场汇报等工作, 培养了学生的协作能力和语 
言表达能力。第二学期教学过程中, 授课教师要求学生通过思维导图对学习章节进行总结, 以提升 整理、总结知识点的能力; 同时还要求学生根据指定课程内容自主设计课堂, 激发学生学习自主能 动性。各项教学活动均体现了师生共同参与, 活动内容与教材相辅相成, 达到了课程学习与能力提 升同频共振的目的。

授课教师还注重将化学领域的前沿知识贯穿于整个教学活动当中, 在课堂内外不定期向学生输 出相关知识。例如: 在课堂上讲述电化学一章时, 授课教师结合2019年 “诺贝尔化学奖一一锂离子 电池的研发” 这一科研热点, 引导学生了解锂离子电池的研究进展, 讨论电池研究过程中存在的问 题及解决思路; 课下, 授课教师结合学生学习情况, 在课程微信群中分享化学专业期刊、化学常用 软件、化学科普知识、化学名家介绍等内容链接, 以增强学生对化学领域的好奇心和自信感, 激励 学生 “见贤思齐焉”，鼓励学生适时与大家分享见闻(图2)。

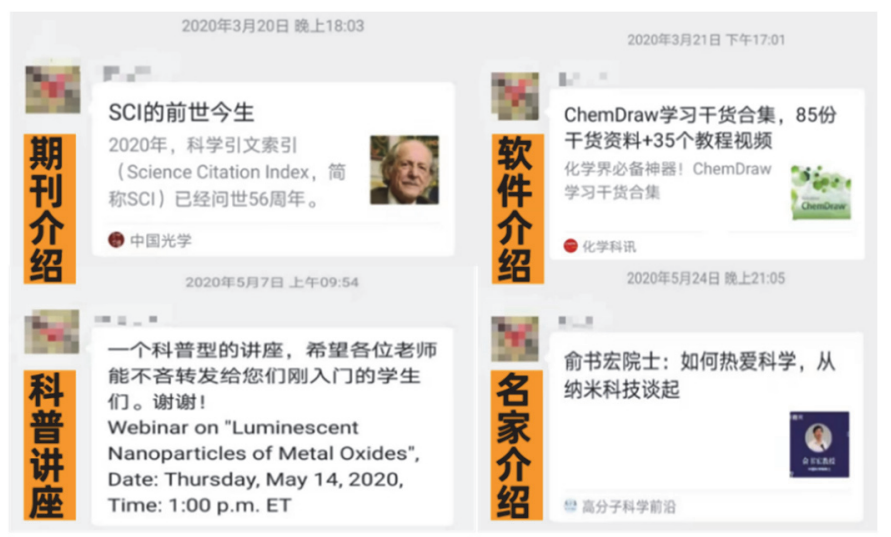

图2 化学领域最新信息分享

\section{1 课堂内容延伸}

为了培养学生自主钻研、深入了解问题的能力和兴趣, 养成追求透过表象看本质的学习习惯, 无机化学课程授课教师依据教学内容对学生的课程学习提出了新要求, 希望学生能够更多地了解与 课程教材内容相关的课外知识, 自主将课堂内容加以延伸。在此项活动中, 教师引导学生课外分别 以道尔顿的生平、准晶体的相关知识以及溶剂热及其发明者等为主题, 经过文献查阅、分析和充分 讨论后, 撰写成书面材料, 进一步组织为PPT在班级活动中进行汇报, 使全班同学都能够在课程学习 之余了解著名科学家的事迹、相关化学发展史等背景和与课程内容相关知识的发展历程(图3)。

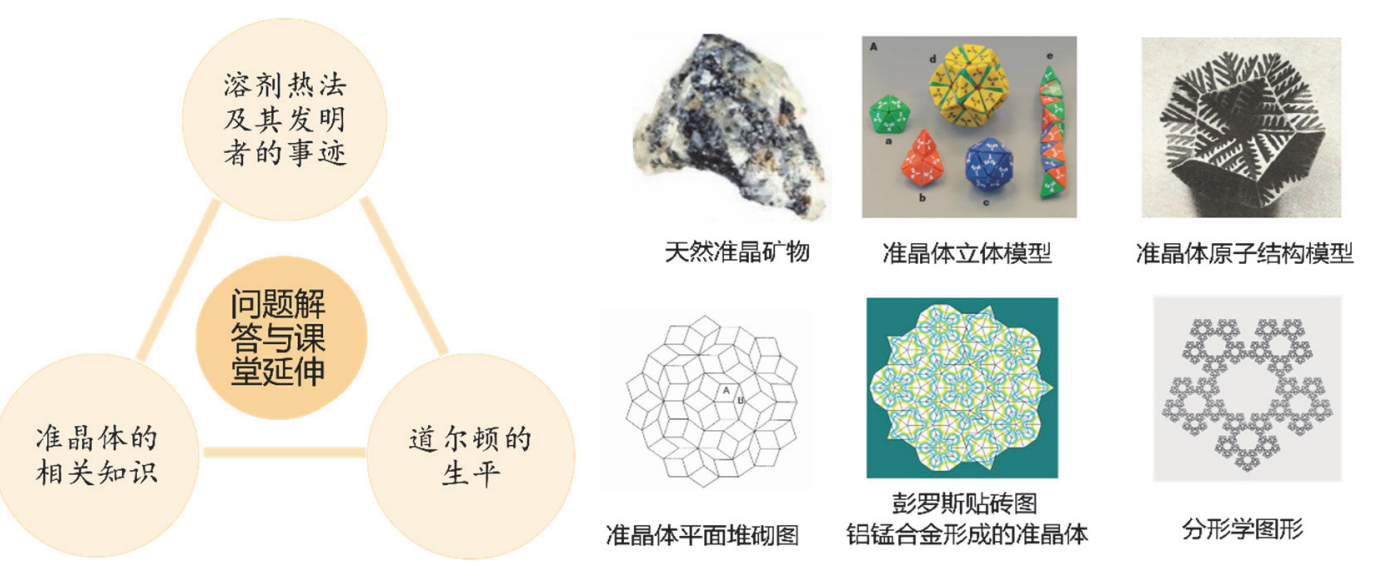

图3 课堂内容延伸活动 
例如: 授课教师对原子晶体部分进行授课时, 有学生对教师课件中 “准晶体是晶体范畴下的一 个分支” 和课本上 “准晶体是介于晶体与非晶体之间的一种物质” 两种观点提出疑问, 认为是两种 矛盾的观点。授课教师并未立即给出准确答案, 而是选择让提问的两位同学在课下进行深入探究并 为班级同学解答问题。通过讲解和讨论, 同学们了解到这种矛盾观点产生的渊源: 1982年Dan Shechtman在Al-Mn合金急冷相中发现了在科学界引起了巨大轰动的、具有五重旋转对称性合金相、 结构长程有序但无平移对称性的准晶 ${ }^{[6]}$, 这一发现使国际晶体学联合会对晶体的原定义进行了更 改。在整个过程中, 学生们通过对大量英文文献、图片的解读和分析, 总结出两种观点的存在理由: (1) 准晶体是晶体一准晶体与晶体都具有各向异性特点且原子排列长程有序, 金属准晶和晶体 一样具有固定的熔点, 且准晶体在TEM和XRD中都表现出明锐的亮点或者峰; (2) 准晶体不是晶 体一一准晶体的原子排列无周期性且有晶体所不允许的五次旋转对称性 ${ }^{[7]}$, 金属准晶导电导热能 力差, 像非晶体物质易破裂, 并具有逐渐转变为晶体的趋势。

回顾了 “准晶体是否为晶体” 这一科研热点问题的探索历程后, 学生对准晶体有了比较充分的 认识, 最后有接近半数的学生从原本支持 “准晶体不是晶体” 转变为支持 “准晶体是晶体”。这一 活动使学生意识到在课堂中应该用质疑的观点进行学习, 勇于挑战权威, 敢于提出自己的疑问, 将 课堂与学科前沿联系起来去思考问题、解答问题, 而不是仅仅局限于课堂。

\section{2 主题研讨与汇报}

查阅化学工具书及文献是化学工作者的必备工作方法, 也是一名化学专业学生应该具备的基本 素养, 因此授课教师有意识地去培养学生搜集资料、查阅文献的能力就显得尤为重要 ${ }^{[8]}$ 。在大一第 一学期的后半学期, 授课教师根据教材重点内容精选出七个课题, 学习小组各选一个课题, 通过自 主查阅相关文献资料、进行分析研讨后, 完成一份 5000 字左右的课题报告。各小组由小组长分配任 务, 确保每位学生都能够参与其中, 并将参与学生在活动的分工和参与程度作为学生平时成绩的考 核指标之一。尽管学生第一份课题报告的质量和水平还有待于提高, 但无疑是后续的探索性学习的 良好开端。

以图4中 “徐光宪的生平及学术贡献” 课题为例对该项教学活动进行说明, 课本第五章 “原子结 构和元素周期律” 中徐光宪提出的关于多电子原子能级高低次序的 $(n+0.71)$ 规则提及, 对于一个能 级, 其 $(n+0.71)$ 值越大, 则能量越高, 且该能级所在能级组的组数就是 $(n+0.71)$ 的整数部分。研讨小 组将课题分为 “生平简述” “ $n+0.71$ 规则的由来” “分离稀土的串级萃取理论” “对物质结构与性 质的相关研究” 和 “溶液络合物的相关研究” 等五个部分进行研讨, 9位小组成员中有 5 人负责各部 分的资料查找与论文撰写, 有 2 人负责汇总、整理与完善, 有 2 人负责 PPT的制作, 组长负责汇报。整 个过程小组成员各司其职, 在六周内圆满地完成了对此课题的研究, 更为关键的是, 在此过程中学 生们被老一辈科学家为国家发展倾心尽力、孜孜以求的爱国精神和奉献精神所感动, 为老一辈科学 家在稀土领域取得的成绩而自豪, 民族自豪感和责任心油然而生 ${ }^{[5]}$ 。

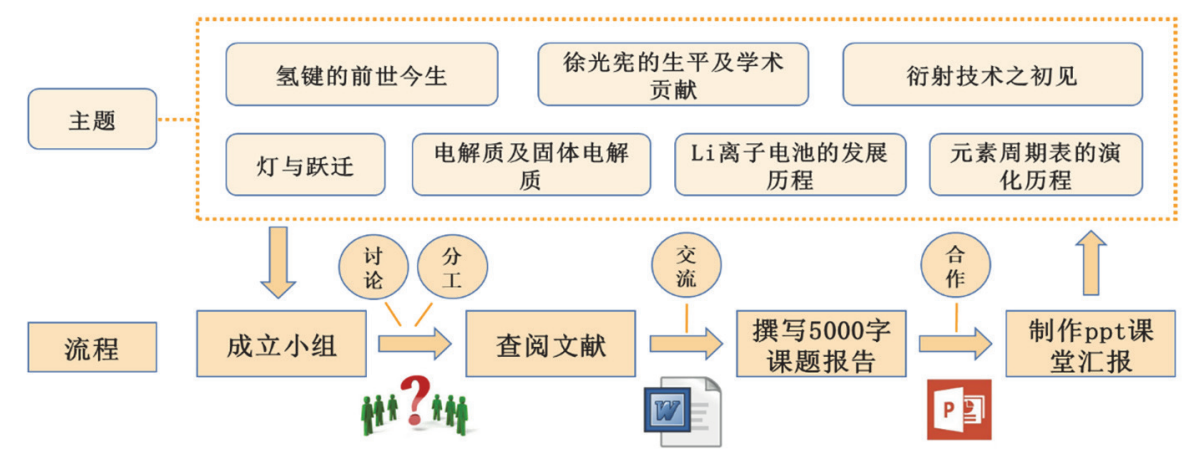

图4 研讨与汇报主题及流程 
更值得一提的是, 之后有两位学生将在课堂教学活动中所学到的技能与大一第二学期所学习的 硫元素相关知识相结合, 成功撰写并发表了 “榴莲的自白一一臭臭的味道下是一颗真诚的心” 科普 论文。文章中提到, 榴莲的臭味主要是由于香气中混杂有少量二硫化物、三硫化物和四硫化物, 包 含乙硫醇 $(0.99 \%)$ 和丙硫醇 $(0.43 \%)^{[9]}$ 。除了人们熟知的硫磺, 这无疑又是一个硫元素在生活中的具体 表现。

\section{3 思维导图与章节总结}

对于刚刚接触大学专业课的化学专业学生而言, 无机化学课程内容的广度和深度较中学化学学 习内容都有很大的提高和扩展。学生如果不能很好地从 “题海战术” “老师主讲” 的课堂模式中迅 速转换过来, 找到适合自己、适应大学课堂的学习方法, 易感到无措、迷茫, 就难以体会到获得感、 成就感, 不利于整个大学期间个人能力的发展。

大一第二学期无机化学课程内容交互性强, 对培养学生自主学习能力和科学思维方法是一个新 的挑战。为了让学生从 “以老师为中心” 转换为 “以自己为中心”, 准确理解教材内容教材, 以辩 证的方式学习和整理课堂知识, 授课教师在 “无机化学(下)” 课程的教学过程中开展了新的课堂活动 一一自主绘制思维导图 ${ }^{[10]}$ 进行章节总结。在每一章节教学结束后, 要求每位学生使用思维导图梳理、 总结章节知识点, 分清重难点, 并由小组代表在辅导课上进行总结交流。通过该项活动, 学生的知 识总结能力、图形表现水平、交流沟通能力专业知识的掌握程度和软件应用水平都得到了显著提升。 图5为班级某组学生绘制的氧化还原反应章节思维导图, 尽管构图和制作水平还有待提高, 但该章内 容的基本框架和相互关联基本清楚。

\section{4 学生自主设计课堂}

由学生充当课堂教师, 自主规划课堂教学内容, 将灌输式学习转换为主动的 “教与学”, 授课 教师对教学过程进行指导和评价, 及时梳理补充、归纳总结。这种 “以学生为中心” 的课堂教学模 式, 为学生自主学习和个性发展提供了空间。在大一第二学期的后半学期, 学生已经掌握化学基本 原理、物质结构基础和非金属元素化学知识的基础上, 授课教师将课堂交给学生, 在铜锌副族元素、 铬锰副族元素、钛钒副族元素、铁系元素等多个章节的教学活动中采用了学生自主设计课堂的学习 方式。授课教师在课前提出教学内容要求并提供部分教学资料, 由学生根据自己的学习思路, 自主 设计课堂并授课。教师则通过组织学生对教学内容进行讨论, 绘制教学内容框架图对课程内容进行 总结、提炼和强化, 从而关注到每一位学生的学习状态。为了保证有充足的课时, 授课教师也将每 周一次的辅导课时纳入了教学活动当中。

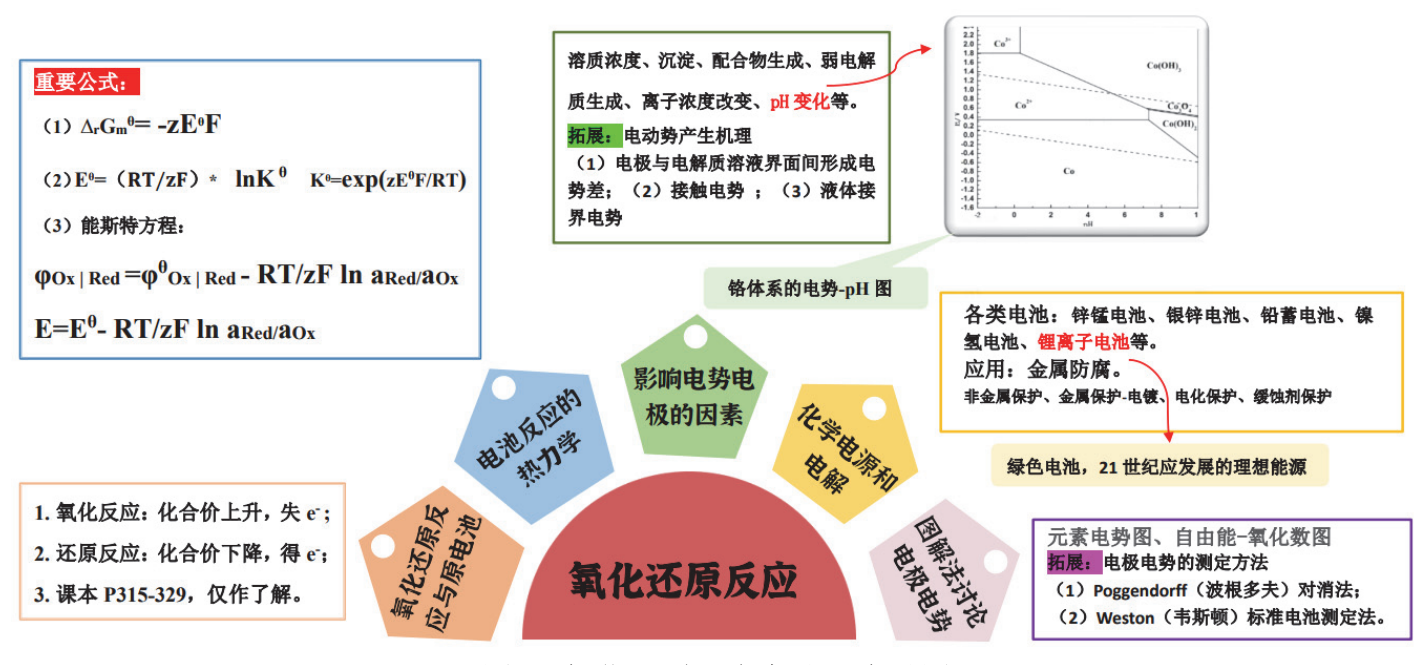

图5 氧化还原反应章节思维导图 
在整个活动中, 每一位主讲学生都做了非常充分的准备。其中, 本文的第二作者充分利用自己 家乡———中国镍都” (甘肃省金昌市)的矿产资源优势, 主动负责过渡元素概述及铜副族元素的讲 解。为此主讲人专门进行了为期一周的考察, 设计了一堂别开生面的无机化学课: 过渡元素主要由 黑色金属和有色金属组成, $d$ 轨道部分充满且性质处于金属与非金属之间, 因而可失去部分内层电子 而存在可变化合价, 并易形成络合物, 如 $\mathrm{Ni}^{2+}$ 溶液加入适量氭化钾溶液可生成 $\left[\mathrm{Ni}(\mathrm{CN})_{4}\right]^{2-}$ 黄色溶液, 氧化钾过量最后生成 $\left[\mathrm{Ni}(\mathrm{CN})_{5}\right]^{3-}$ 红色溶液。且通过观赏矿山实地与博物馆的采风相片(图6)与视频, 同学们对于元素化学产生了极大的兴趣, 并对我国的矿物产量与多项成熟的冶炼技术有了更为直观 的认识, 增强了对我国化学事业的自信心与自豪感。
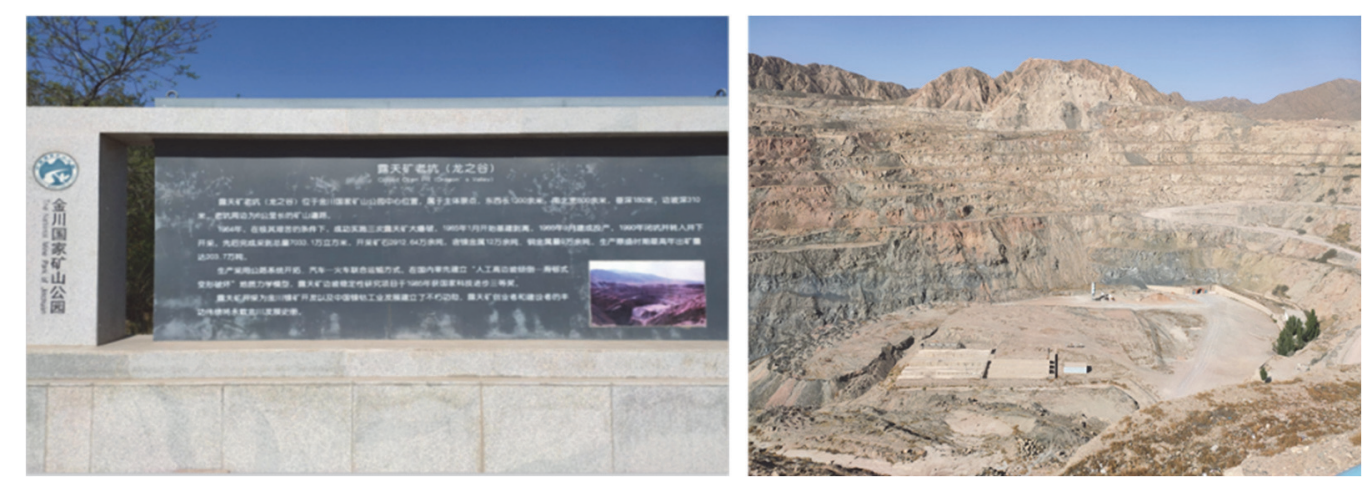

图6 学生课前实地考察

此外, 主讲的同学还注重将授课内容与无机化学实验课相结合, 适时地插入一些中国大学 MOOC 中的精品实验视频, 通过实验教学视频, 引导同学们将课本知识与具体实际相结合, 思考理 论与实验的统一与差异, 加深了对化学元素各种性质的理解。例如: 在 $\mathrm{Cr}^{3+}$ 的鉴定中, 向前期制备 的黄色溶液 $\left(\mathrm{Cr}^{3+}+4 \mathrm{OH}^{-}\right.$(过量) $=\mathrm{Cr}(\mathrm{OH})_{4}^{-}$(亮绿色)、 $2 \mathrm{Cr}(\mathrm{OH})_{4}^{-}+3 \mathrm{H}_{2} \mathrm{O}_{2}+2 \mathrm{OH}^{-}=2 \mathrm{CrO}_{4}^{2-}$ (黄色) + $8 \mathrm{H}_{2} \mathrm{O}$ ) 中加入 $\mathrm{H}_{2} \mathrm{O}_{2}$ 、戊醇和 $\mathrm{HNO}_{3}$ 溶液, 若溶液呈纯蓝色, 则可证明待测溶液中存在 $\mathrm{Cr}^{3+}$ 离子(图 7)。但在实际实验操作过程中, 有的学生实验结果并未出现纯蓝色, 原因在于他们在加入双氧水和 酸之后方加入戈醇, 中间产物 $\mathrm{CrO}\left(\mathrm{O}_{2}\right)_{2}$ 在水中快速分解, 而戊醇应在加入双氧水和酸之前或两者之 间加入，使 $\mathrm{CrO}\left(\mathrm{O}_{2}\right)_{2}$ 被萃取进入有机相，阻隔其与水的接触。

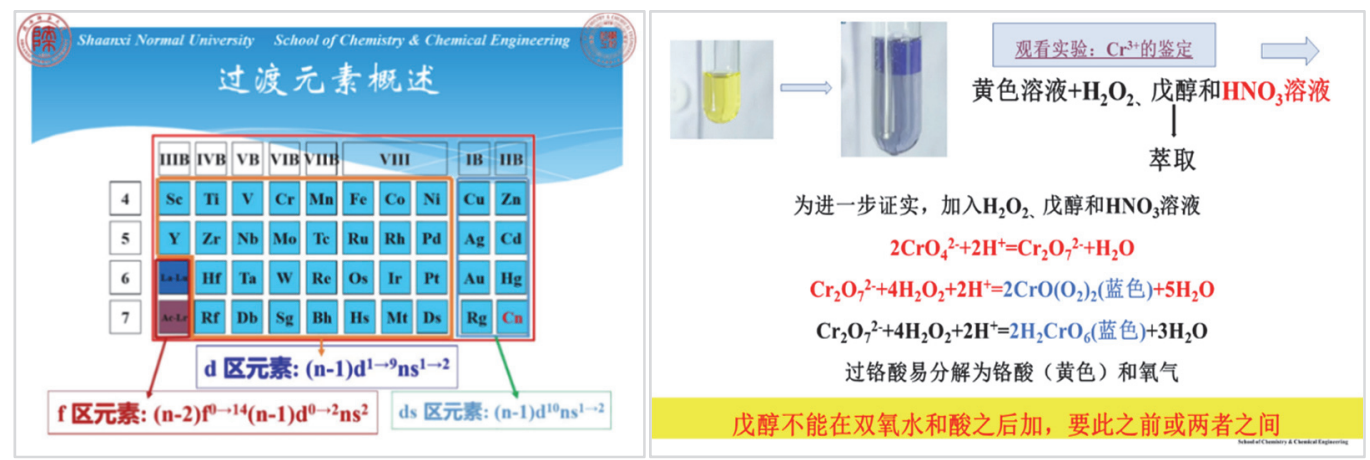

图7 部分学生授课PPT图片

\section{2 教学活动满意度调查}

\section{1 专题采访}

在四项课堂教学活动中, 学生普遍反映在自主设计课堂活动中的准备最充分、体验感最强烈。 通过对他们进行专题采访, 我们可以获知学生对这一课堂教学活动的体验与感受(采访问题与回答详 
情见图8)。在学生看来, 自主设计课堂这一教学模式的最大特点及优势在于给学生提供了一个授课 的平台, 尤其是对于希望未来从事教育教学工作的学生。与此同时, 这种教学模式促使学生仔细研 读课本, 对于知识的把握求精、求深、求广, 也锻炼了学生的文字、语言表达能力和胆量。

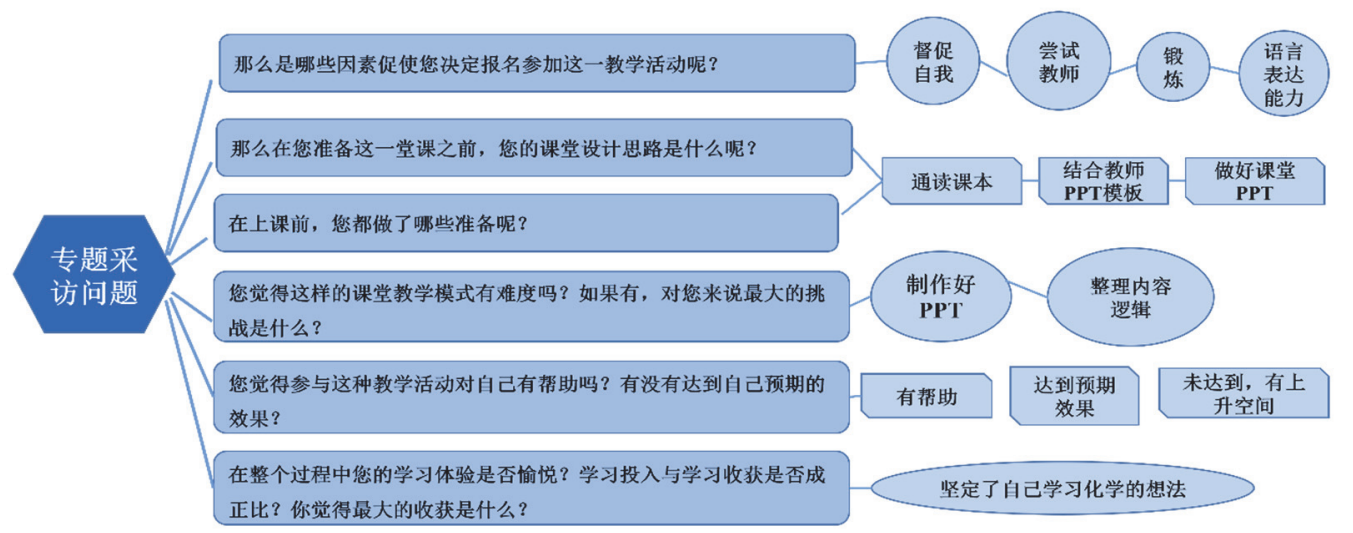

图8 学生自主设计课堂专题采访内容及结果

学生也给出了改进和完善这一教学活动的建议: (1) 对于报名讲课的学生, 通过适当方式进行 篎选以提高授课质量和效率; (2) 学生授课前进行资料审查和预讲有助于进一步提高教师对课堂的 整体情况的把握程度; (3) 同学间应加强互动, 相互纠错, 相互交流, 以提升学生的参与度, 使每一 位学生对相关知识的掌握有所提高; (4) 小组合作模式分工明确, 有助于自主设计课堂的推广, 也可 提高学生的参与度。

\section{2 问卷调研}

为了准确把握学生在多模态建构下的课堂教学活动中的学习状况, 我们有针对性地设计了问卷, 并进行调研, 收集了学生们的感受与建议。此次问卷包括8道客观题、6道主观题, 共14道题, 全班55 名学生都参与了此项调研。我们对客观、主观问题两个部分的问卷进行了整理分析, 具体情况如下。

\subsection{1 客观问题}

图9中列出了客观问题的问题概要与回答情况 ${ }^{[11]}$ 。对问题1、2( “参与课堂活动之前会很认真地 做准备” “准备课堂活动前经常会积极、主动与同学老师交流探讨” ) “赞同” 的比例分别为 $81.82 \%$ 、 $63.64 \%$, 表明学生参与课堂活动的主动性较高, 能够积极去发现问题、解决问题; 对问题 3 和 4 ( “乐 于在无机化学课堂教学中接受不同的教学模式” “在同学对问题进行解答时对同学所讲内容非常感 兴趣” ) “赞同” 的比例分别为 $78.18 \% 、 72.73 \%$, 说明学生参与情况良好, 整体上对于这种多模态建 构下的课堂教学活动认可度高, 课堂效果令人满意。
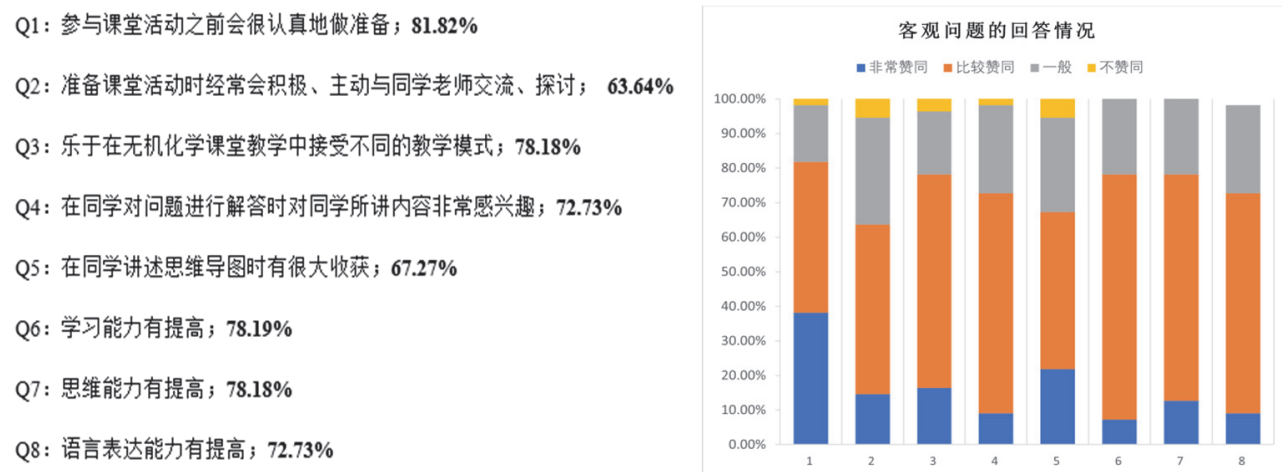

图9 调查问卷中客观问题及调查结果 
对学生的学习收获与效果的调查结果见图 10, 在四项课堂教学活动中, 受学生认可度较高的是 思维导图与章节总结, 有 $67.27 \%$ 学生表示 “在同学讲述思维导图时有很大收获”。学生普遍反映其 学习能力、思维能力、语言表达能力都有不同程度上的提高, 达到了开展不同形式课堂教学活动的 预期效果。

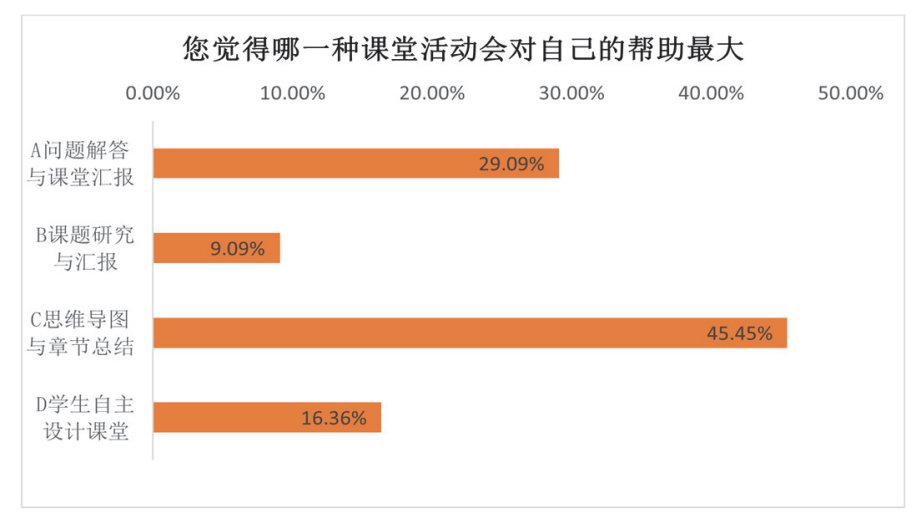

图10 对不同课堂活动的认可情况

\subsection{2 主观问题}

(1) 小组体验与感受。在四种课堂教学活动中有三种采用了小组活动模式, 整体上学生对小组 学习的体验感良好, 认可度高。但是, 这种模式存在的小组讨论与任务分配不及时、分工不明确、 成员间交流不充分等问题依然突出(表1), 建议教师在组织活动过程中能够更多地、更公平地体现过 程考核。

表1 小组合作模式的体验与感受调查结果

\begin{tabular}{|c|c|c|c|c|}
\hline 问题 & \multicolumn{4}{|c|}{ (可多选)在进行小组合作过程中, 您觉得您遇到的最大困难是什么? } \\
\hline 选项 & A 小组讨论、任务分配不及时 & B 小组分工不明确 & $\mathrm{C}$ 小组成员之间没有适当交流 & D 其他(填空) \\
\hline \multirow[t]{2}{*}{ 概率 } & $50.91 \%$ & $41.82 \%$ & $61.82 \%$ & (1) 研究课题陌生, 准备起来比较 \\
\hline & & & & 吃力; (2) 小组成员的积极性不高 \\
\hline
\end{tabular}

(2) 学生对课堂的关注情况。以学生为 “课堂主讲人”，从“授课方式” 与关注内容” 两个方 面进行了调查分析。据图11可知, 大部分学生还是表示更喜欢传统的以老师主讲的教学方式。为什 么会出现这样的结果呢? 除了学生自身的主观原因, 是否还因为这种课堂教学活动无法满足学生对 快速掌握知识、提高学习成绩、应对期末考试的需求呢? 学生进入大学以后, 是否还对中学时期 “灌 输式” 课堂教学模式、“题海战术” 存在依赖性? 该如何改进课堂教学活动模式, 做好学生从中学 到大学的过渡？这些也是在此次系列课堂教学活动中暴露出来的问题, 还有待于进一步分析。
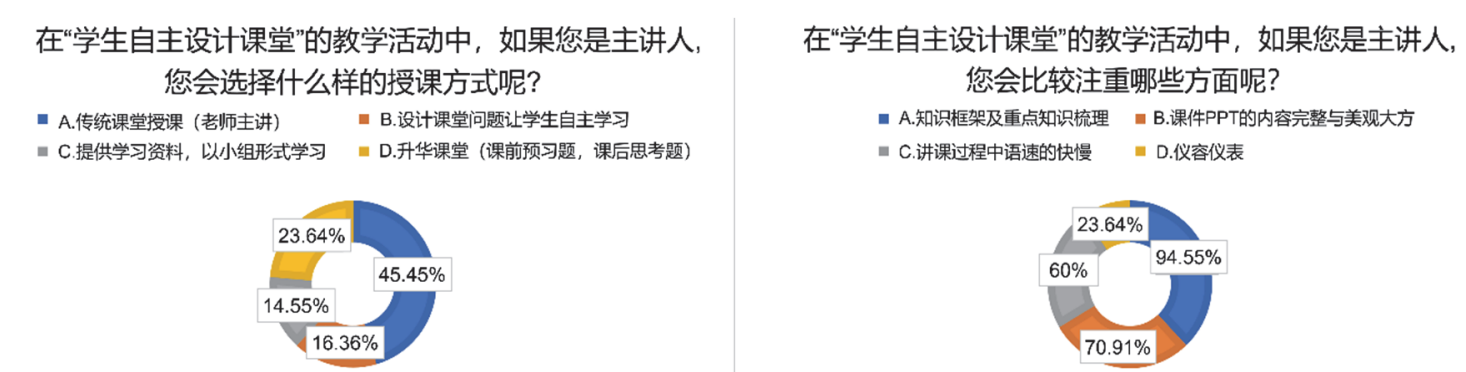

图11 学生对课堂的关注情况调研结果 
因此, 我们对学生未参与课堂活动的原因进行调查(表 2), 其中 “更喜欢传统教学方式” “没有 做过, 不知道怎么开始” 是最为主要的原因。此外, 学生也表示, 在课堂中会更注重知识框架和重 点知识的梳理、课件内容完整程度与美观大方, 以及讲课过程中语言表达。以上这些为教师提高课 堂质量、改进课堂活动方式提供了第一手建议。

表2 对未参与的活动进行原因分析

\begin{tabular}{|c|c|c|c|c|}
\hline 问题 & \multicolumn{4}{|c|}{ (可多选)对于未参与的课堂活动, 您觉得对您来说当时的原因或者困难是什么? } \\
\hline 选项 & $\begin{array}{l}\text { A 更喜欢传统教学方 } \\
\text { 式(老师主讲) }\end{array}$ & $\begin{array}{l}\mathrm{B} \text { 没有电脑等工具, } \\
\text { 课堂准备受阻 }\end{array}$ & $\begin{array}{l}\mathrm{C} \text { 没有做过, 不 } \\
\text { 知道怎么开始 }\end{array}$ & D 其他(填空) \\
\hline 概率 & $60 \%$ & $9.09 \%$ & $52.73 \%$ & $\begin{array}{l}\text { (1) 当时还没有想法; (2) 时间不够; (3) 同学讲不知道 } \\
\text { 重难点; (4) 难以正确理解知识点 }\end{array}$ \\
\hline
\end{tabular}

(3) 课堂活动的改进建议。如何让更多的学生愿意跳出 “老师主讲” 的课堂舒适圈, 参与到课堂 活动中来? 学生也都给出了许多具体可行的改进建议, 下面列举了一些典型回复供教师们参考。

“以学生为主导, 通过小组讨论、课题汇报、习题讲解、学生授课等活动能够充分发挥学生主 观能动性。”

“多引导学生将课堂内容与社会生活生产实际相联系, 以便能学以致用。”

“多采取小组模式教学活动, 尽可能让更多的学生汇报讲解, 调动同学积极性。”

“课堂主讲人多设计开放性问题, 并组织分析与讨论, 增加同学互动次数。”

\section{3 结语}

多模态建构下的无机化学课程教学模式以推动学生自主学习为目的, 助力学生摆脱 “你讲我听” 的灌输式课堂学习思维, 在学习中实现从 “接收者” 到 “学习者” 的转变。从教学活动的开展情况 与调查结果来看, 学生以十分积极的态度参与了多模态建构下的课堂教学活动, 并获得了体验。 相比于传统教学, 这种课堂模式更加注重提升学生的思维能力与表达能力, 将 “学” 与 “教” 相融 合, 让学生 “学得更会, 更会去学” 。但这种课堂教学活动在满足学生快速掌握知识、提高学习成 绩、应对期末考试的需求上仍存在一定的局限性, 这也成为了部分教师和学生不愿或难以跳出传统 教学模式这一 “舒适圈” 的重要原因。

多模式自主学习不仅对学生的技能学习与知识理解有一定的要求, 在时间的安排与调整上也是 一个挑战。在教学过程中教师鼓励学生扎实专业基础知识、强化学习能力, 积极参与小组合作为主 的各项教学活动, 引导学生将不同教学活动的任务进行细化与组合后, 再落实到个人, 帮助学生有 效合理利用课余时间, 充分地保证了学生在有限的时间内实现自身能力的多维度提升。

目前教学活动开展过程中仍存在一些问题, 学生们希望授课教师在备课时, 能够更多地关注如 何让学生学会自己探索知识、深挖教材, 在其中学有所得、学有所感, 并注意提升教学内容的前沿 性, 在内容深化的同时注意教与学携手共进, 以此扩展学生认知与开拓其思维。学生们则要在课程 学习中勇敢面对挑战、探索创新。相信在师生的共同努力下, 未来的无机化学教学将会呈现出更为 有利于学生发展、更为丰富的模式。

\section{参 考 文 献}

[1] 李襄宏, 张丙广, 唐定国, 黄涛. 绿色科技, 2019, No. 17, 276.

[2] 教育部关于狠抓新时代全国高等学校本科教育工作会议精神落实的通知. [2018-08-22]. http://www.gov.cn/zhengce/zhengceku/2018- 
[3] 朱怡中, 王耀南, 徐兆文. 江苏政协, 1999, No. 6, 36.

[4] 吴岩. 中国大学教学, 2018, 340 (12), 6.

[5] 汪羽翎, 马荔, 谢少艾, 张卫, 魏霄, 尹屹梅, 陈虹锦. 大学化学, 2021, 36 (3), 32.

[6] Shechtman, D.; Blech, I.; Gratias, D.; Cahn, J. W. Phys. Rev. Lett. 1984, 53, 1951.

[7] 陈波. 化学教学, 2012, No. 1,3.

[8] 郭霖, 隋坤艳, 胡浩, 王久兴, 王逸凡, 张小艳, 彭乔虹, 随欣. 大学化学, 2021, 36 (8), 2009004.

[9] 苏敏, 杨丽锦. 大学化学, 2020, 35 (11), 155.

[10] 陈亚苻, 宁清茹. 大学化学, 2017, 32 (3), 24.

[11] 高琼芝, 刘英菊, 张声森, 杨思源, 蔡欣, 刘海峰, 周晓华. 大学化学, 2021, 36 (7), 2010065. 